Review Paper (Invited)

\title{
Concave Surface Boundary Layer Flows in the Presence of Streamwise Vortices
}

\author{
Sonny H. Winoto ${ }^{1}$, Tandiono ${ }^{1}$, Dilip A. Shah ${ }^{1}$ and Hatsari Mitsudharmadi ${ }^{2}$ \\ ${ }^{1}$ Department of Mechanical Engineering, National University of Singapore \\ 9 Engineering Drive 1, Singapore 117576, Singapore, mpewinot@nus.edu.sg \\ ${ }^{2}$ Temasek Laboratories, National University of Singapore \\ 5A Engineering Drive 1, Singapore 117411, Singapore
}

\begin{abstract}
Concave surface boundary-layer flows are subjected to centrifugal instability which results in the formation of streamwise counter-rotating vortices. Such boundary layer flows have been experimentally investigated on concave surfaces of $1 \mathrm{~m}$ and $2 \mathrm{~m}$ radius of curvature. In the experiments, to obtain uniform vortex wavelengths, thin perturbation wires placed upstream and perpendicular to the concave surface leading edge, were used to pre-set the wavelengths. Velocity contours were obtained from hot-wire anemometer velocity measurements. The most amplified vortex wavelengths can be pre-set by the spanwise spacing of the thin wires and the free-stream velocity. The velocity contours on the cross-sectional planes at several streamwise locations show the growth and breakdown of the vortices. Three different vortex growth regions can be identified. The occurrence of a secondary instability mode is also shown as mushroom-like structures as a consequence of the non-linear growth of the streamwise vortices. Wall shear stress measurements on concave surface of $1 \mathrm{~m}$ radius of curvature reveal that the spanwise-averaged wall shear stress increases well beyond the flat plate boundary layer values. By pre-setting much larger or much smaller vortex wavelength than the most amplified one, the splitting or merging of the streamwise vortices will respectively occur.
\end{abstract}

Keywords: Görtler vortices, concave surface, boundary layer, instability, wall shear stress, hot-wire anemometer.

\section{Introduction}

Concave surface boundary layer flows are subjected to centrifugal instability due to the imbalance between radial pressure gradient and centrifugal force. This instability manifests itself as streamwise counter-rotating vortices inside the boundary layer flows and known as Görtler vortices (named after Görtler [1] who first analytically predicted their occurrence).

Görtler vortices will occur in concave surface boundary layer flows as shown in Fig. 1, if the so- called Görtler number $\mathrm{G}_{\theta}$, as defined by Smith [2]:

$$
\mathrm{G}_{\theta}=\left(\mathrm{U}_{\infty} \theta / v\right) \sqrt{\theta / \mathrm{R}}
$$

exceeds a critical value $G_{\theta c r}$, where $v$ is the fluid kinematic viscosity, $\theta$ the momentum thickness based on Blasius flat plate boundary-layer solution, $\mathrm{U}_{\infty}$ the free-stream velocity, and $\mathrm{R}$ the concave surface radius of curvature. The vortices will be amplified downstream resulting in a three-dimensional boundary-layer due to streamwise momentum distribution which causes spanwise variation in the boundary-layer thickness, due to the formation of the so-called "upwash" region, where low momentum fluid moves away from the surface, and the so-called "downwash" region, where high speed outer fluid moves towards the surface (Fig. 1). At "upwash", the boundary-layer is thicker and the shear stress is lower than those at "downwash".

Since concave surfaces exist in many fluid engineering applications, such as turbine blades and aerofoils, the effects of Görtler vortices on boundary layer development, heat transfer and possibly deposition cannot be ignored.

Recently, flows over dimpled surfaces, which are three-dimensional concave surfaces [3], also attracted some attention due to the potential applications in heat transfer enhancement [4] and possible drag reduction.

Since the analytical work of Görtler [1], there have been many experiments on Görtler vortices. The early works were mainly in visualizing these vortices as reviewed by Winoto et al. [5].

The effects of Görtler vortices on heat transfer was first investigated by McCormack et al. [6] who reported 100 to 150\% increase in Nusselt number on a concave surface in the presence of such vortices, compared with a reference flat plate. An

Accepted for publication December 16 2010: Paper number R10046S

Corresponding author: Sonny H. Winoto, Associate Professor, mpewinot@nus.edu.sg

This paper was presented at 2010 International Conference on Pumps and Fans, October 18-21, 2010, Hangzhou, China 
empirical relationship for laminar heat transfer enhancement by the vortices was proposed by Kan et al. [7] based on one set of measurements of mass transfer from a naphthalene-coated blade in a turbine cascade. They correlated the ratio of actual Nusselt number to that of flat plate as $\left(1+\mathrm{G}_{\theta}\right)^{1 / 2}$. Since then, there has been relatively little work on the thermal effects of Görtler vortices. The more recent works were done by Crane and Sabzvari [8], Crane and Umur [9], Momayez et al. [10-11].

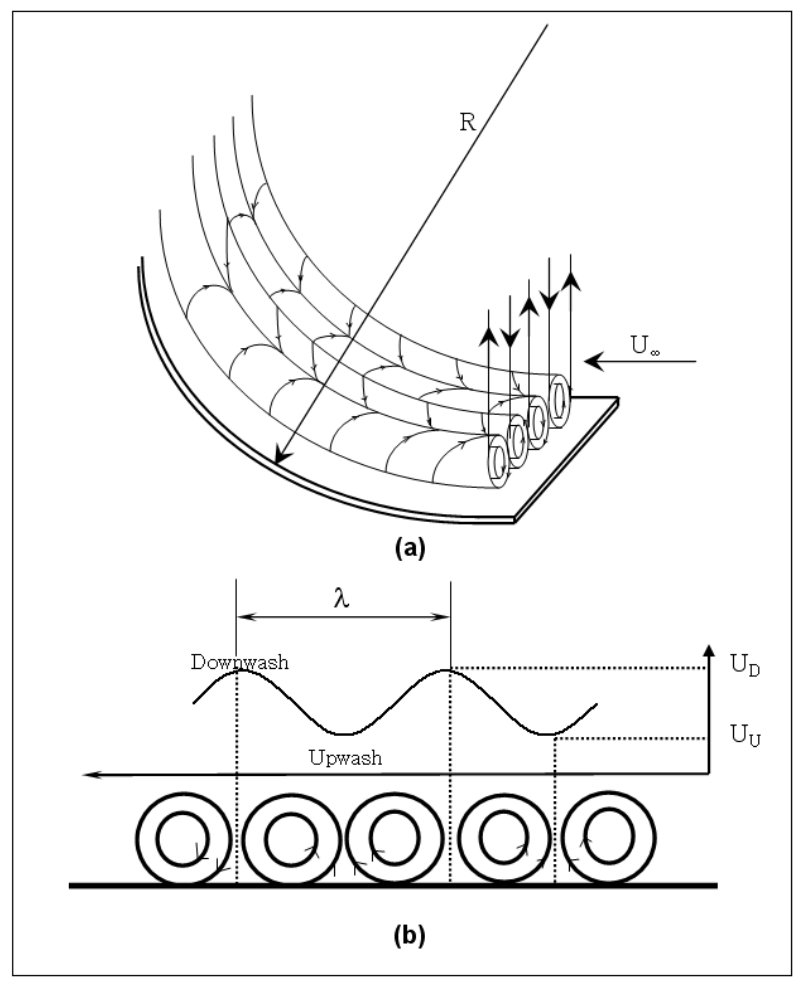

Fig. 1 Sketch of Görtler vortices on a concave surface: (a) Flow configuration, and (b) Spanwise distribution of mean streamwise velocity $\mathrm{U}$ showing the definitions of vortex wavelength $\lambda$, downwash, and upwash regions.

Computational works on Görtler instability were initially focused on establishing a unique stability curve. Floryan and Saric [12] found that the neutral curve appears to asymptotically level off at $\mathrm{G}_{\theta, \mathrm{cr}}=0.4638$ which can be considered as a critical value. Finnis and Brown [13] found that the minimum point of the unstable region occurs at $\mathrm{G}_{\theta}=1.38$ for the dimensionless wave number $\alpha \theta=0.28$. Different values of $\mathrm{G}_{\theta, \mathrm{cr}}$ were also obtained from experimental works. Moreover, Kottke and Mpourdis [14] did not detect any sign of instability when the screens that act as a source of disturbance were placed sufficiently far upstream. The above results show that the concept of a unique stability curve is not tenable in Görtler problem. The growth, as well as the wavelength selection mechanism, of Görtler vortices is fully governed by the receptivity process, as discussed by Denier et al. [15] and Bassom and Hall [16].

Assuming that only the most amplified vortices will occur in experiment, a method based on the Görtler vortex stability diagram (of Smith [2], for example) can be used to predict the experimental wavelength of Görtler vortices. In this method, the non-dimensional wavelength parameter $\Lambda$ is defined as:

$$
\Lambda=\left(\mathrm{U}_{\infty} \lambda / v\right) \sqrt{\lambda / \mathrm{R}}
$$

where $\lambda$ is the most amplified Görtler vortex wavelength, and $\Lambda$ represents a family of straight lines which cross the Görtler vortex stability diagram of $\mathrm{G}_{\theta}$ versus $\alpha \theta$. ( $\alpha \theta$ is called dimensionless wave number and $\alpha(=2 \pi / \lambda)$ is called wave number). Luchini and Bottaro [17] found that the most amplified wavelengths are for $\Lambda=220$ to 270, while Floryan [18], Smith [2], and Meksyn [19] respectively proposed $\Lambda=210,272$, and 227.

Since the wavelengths of naturally developed Görtler vortices are not uniform, experimental investigations were biased due to the choice of "good" pair of Görtler vortices. Hence, Peerhossaini and Bahri [20], Ajakh et al.[21], Toe et al. [22] and more recently Mitsudharmadi et al. [23] used a series of thin wires placed upstream and perpendicular to the concave surface leading edge to pre-set or "force" the wavelength of Görtler vortices. The pre-set or forced wavelengths of the vortices were found to be uniform and equal to the spanwise distance of the wires.

In this work, which was conducted at the Fluid Mechanics Laboratory of Department of Mechanical Engineering, NUS, hotwire anemometry was used to study concave surface boundary-layer flows in the presence of pre-set wavelength Görtler vortices. The vortex structures were visualized by plotting the contours of the streamwise velocity component data obtained from the hotwire measurements.

\section{Details of Experiment}

The experiments were conducted in transparent curved $60^{\circ}$ and $90^{\circ}$ bend test sections, connected to a low speed, blow down type wind tunnel. A smooth concave test surface is mounted inside the curved test section at $0.05 \mathrm{~m}$ from its bottom surface (Fig. 
2). The test surface of $\mathrm{R}=2 \mathrm{~m}$ is in the $60^{\circ}$ bend test section and that of $\mathrm{R}=1 \mathrm{~m}$ in the $90^{\circ}$. Each bend test section is of rectangular cross-section $(0.15 \mathrm{~m} \times 0.60 \mathrm{~m})$, and 13 vertical wires of $0.2 \mathrm{~mm}$ diameter are placed at $10 \mathrm{~mm}$ prior and perpendicular to the concave surface leading edge to pre-set the vortex wavelength. The wire Reynolds number $\mathrm{Re}_{\mathrm{d}}$ based on its diameter is 28 for $U_{\infty}=2.1 \mathrm{~m} / \mathrm{s}$ and 40 for $U_{\infty}=3 \mathrm{~m} / \mathrm{s}$. Hence, no von Kárman vortex streets were generated behind the wires for both cases.

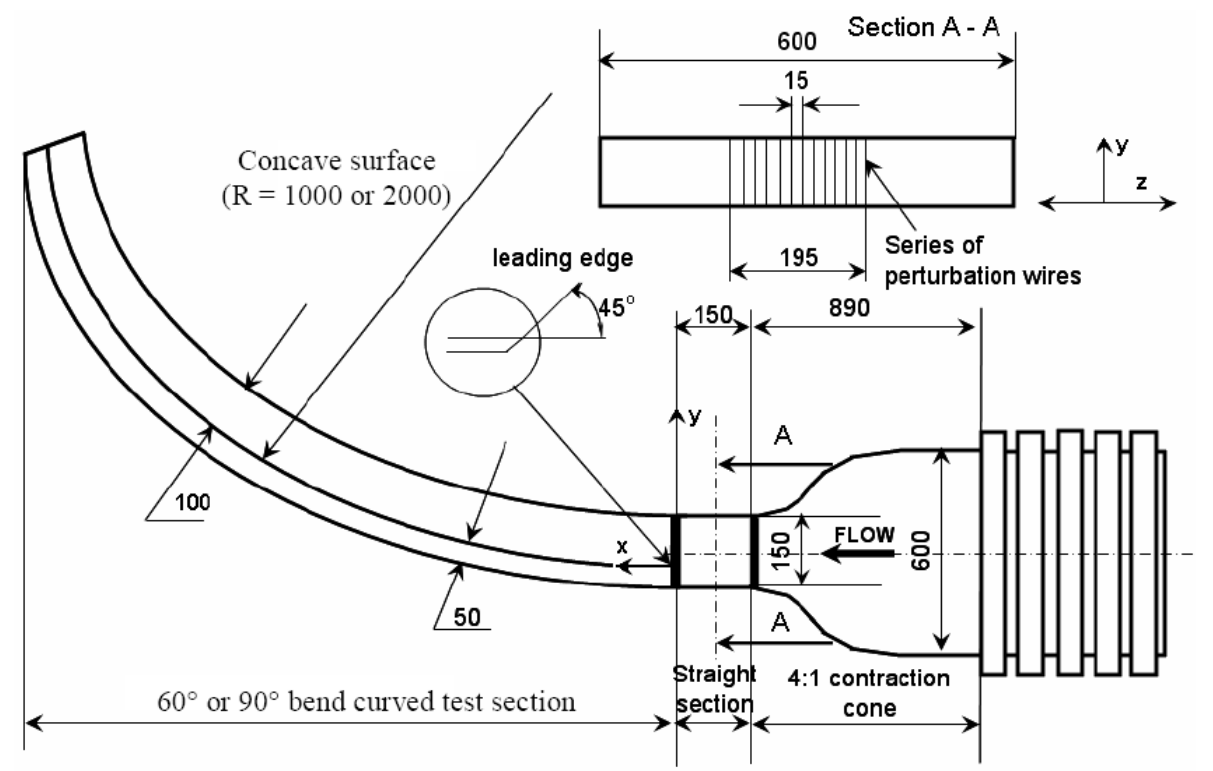

Fig. 2 The wind tunnel, curved test section, and concave test surface (all dimensions are in $\mathrm{mm}$ ).

Since the most amplified wavelength of the vortices can be predicted by using the Görtler vortex stability diagram by setting $\Lambda$ in the range of 200-270, the spanwise distance between the wires was first set at $15 \mathrm{~mm}$ for $\mathrm{U}_{\infty}=2.1 \mathrm{~m} / \mathrm{s}(\mathrm{R}=1 \mathrm{~m})$ and $\mathrm{U}_{\infty}=3.0$ $\mathrm{m} / \mathrm{s}(\mathrm{R}=2 \mathrm{~m})$ so that $\Lambda=249$ and 252 respectively. The free-stream turbulence in each test section is about $0.35 \%$ for $\mathrm{U}_{\infty}=1.0$ to $6.0 \mathrm{~m} / \mathrm{s}$.

A single hot-wire probe (operated in a Constant Temperature Anemometer mode) was used to traverse along a spanwise distance of $60 \mathrm{~mm}$ to obtain the mean and fluctuating streamwise velocity component data. The probe was coupled to a signal conditioner. The signal was low pass filtered at $3000 \mathrm{~Hz}$ and sampled at $6000 \mathrm{~Hz}$ for 21 seconds. The data collected were digitized using an analog to digital converter card DT3016 installed in a personal computer, and further analyzed using the HPVEE software.

A pressure transducer (calibrated against a micro-manometer) was used together with a Pitot-static tube placed in the freestream region for hot-wire calibration. During velocity measurements, the Pitot-static tube was placed in free-stream to monitor the local free-stream velocity. At the end of data acquisition, the probe was placed in the free-stream and calibration was rechecked. A more than $2 \%$ drift for the sensor was not acceptable and the data would be rejected, resulting in the calibration and data acquisition process to be repeated.

The hot-wire probe and Pitot-static tube were mounted on a traversing mechanism. Two stepper motors controlled the mechanism movement along the normal $(y)$ and spanwise $(\mathrm{z})$ directions with $\pm 0.01 \mathrm{~mm}$ accuracy. Measurements on the $\mathrm{y}-\mathrm{z}$ plane were done with step size of $1.0 \mathrm{~mm}$ in the $\mathrm{z}$-direction, while in the y-direction the step size was $0.5-1.0 \mathrm{~mm}$ depending on the boundary-layer thickness at the measurement station.

\section{Results and Discussions}

The development of Görtler vortices in the boundary layers on concave surface of $\mathrm{R}=1 \mathrm{~m}$ and $2 \mathrm{~m}$ is started with the linear and non-linear regions, followed by decay of mushroom structures prior to turbulence. The main differences are on the location of the onset of linear and non-linear regions which are related to the growth rate of the vortices as shown by the maximum value of streamwise disturbance amplitude $\kappa_{\text {umax }}$ (see Eqn. (3)). Hence, discussion on the development of the vortices as represented by the velocity contours on $\mathrm{y}-\mathrm{z}$ and $\mathrm{x}-\mathrm{z}$ planes are focused for $\mathrm{R}=2 \mathrm{~m}$ only.

The $\mathrm{U} / \mathrm{U}_{\infty}$ contours in the cross-sectional $(\mathrm{y}-\mathrm{z})$ plane at some streamwise $(\mathrm{x})$ locations were obtained from the measurement data by using "Tecplot" software, as shown in Fig. 3. For reference, the corresponding Blasius boundary-layer thickness $\delta$ is indicated on the ordinate for each streamwise location. At $\mathrm{x}=200 \mathrm{~mm}\left(\mathrm{G}_{\theta}=2.393\right)$, the contours are wavy in the spanwise direction, indicating the occurrence of Görtler vortices (Fig. 3(a)). The waviness becomes "stronger" as the flow develops downstream indicating amplification of the vortices, for example, at $\mathrm{x}=500 \mathrm{~mm}$ (Figs. 3(c)) and when transformed into horseshoe vortices at $x=600 \mathrm{~mm}$ (Figs. 3(d)). The horseshoe vortices then became mushroom-like structures downstream before breaking down, as the consequence of the non-linear growth of Görtler vortices [24]. It shows the occurrence of the varicose mode of secondary instability. The mushroom-like vortices are clearly shown at $\mathrm{x}=700 \mathrm{~mm}$ (Fig. 3(e)) until $\mathrm{x}=852 \mathrm{~mm}$ (Fig. 3(i)). The vortices start to decay at $\mathrm{x} \approx 800 \mathrm{~mm}$, however at $\mathrm{x}=904 \mathrm{~mm}$ (Fig. 3(i)) the mushroom shapes are still maintained The breakdown of the spanwise structures could be attributed to the increase of mixing due to the onset of turbulence. The mushroomlike structures shown in Figs. 3(e)-(i) reveal the structures of finite amplitude Görtler vortices and the streamwise region in which 
the mushroom-like structures are coherent and dominating the flow. The development of the mushroom-like structures is caused by the strong non-linearity on the $y-z$ plane [24]. Close to the "stem" of the mushroom, low momentum fluid is ejected from the wall and returned back to the wall in the region of maximum shear to form the shape of mushroom hat.

The $\mathrm{U} / \mathrm{U}_{\infty}$ contours on the $\mathrm{x}-\mathrm{z}$ plane (Fig. 4) show streaks of low velocity (upwash) regions in green. The high velocity (downwash) regions occur in the area between wires where the boundary-layer is thinner than in the low velocity regions that occur downstream of each perturbation wire. These agree with Peerhossaini and Bahri [20] who performed an experiment where $\mathrm{G}_{\theta}$ ranged from 2.0 to 7.7 at $\mathrm{U}_{\infty}=2.0 \mathrm{~m} / \mathrm{s}$ for wire spacing of $30 \mathrm{~mm}$, and $\mathrm{R}=0.65 \mathrm{~m}$ concave surface.

Figure 4(d) show three different regions identified as the $1^{\text {st }}, 2^{\text {nd }}$, and $3^{\text {rd }}$ regions based on the disturbance growth rate. Figure 5 shows the growth rate of the Görtler vortices in term of the maximum disturbance amplitude $\kappa_{\mathrm{umax}}$ where $\kappa_{\mathrm{u}}(\eta)$ is defined by Eqn. (3). The smaller growth is initiated at $\mathrm{x}=500 \mathrm{~mm}$ where the inflection point is first observed in the velocity profile at upwash (Fig. 8(a)). This inflection point in the velocity profile can be used to predict the onset of non-linear region. Hence, in Fig. 4(d), the region depicted as the $2^{\text {nd }}$ region is considered as the non-linear region in which the primary disturbance grows at a smaller rate than in the linear or the $1^{\text {st }}$ region.

In the $1^{\text {st }}$ region, the width of the low speed streaks increases gradually until $x \approx 500 \mathrm{~mm}$, which is attributed to the linear growth of Görtler vortices, followed by the $2^{\text {nd }}$ region in which the width of the low speed streaks increases more rapidly. The difference in the width growth rate of the low speed streaks could be due to the transformation from the "wavy" shape into the "horseshoe" vortices that propagate downstream to form the "mushroom-like" structures. This transformation takes place at $\mathrm{x} \approx$ $500 \mathrm{~mm}$, as shown in Fig. 3(c). The width of the low speed streaks that is invariant in the $3^{\text {rd }}$ region indicates the finite amplitude of the disturbances. From the phenomena presented in Figs. 3(a)-(k), it is found that the $3^{\text {rd }}$ region coincides with the region in which the mushroom-like structures are dominant in the boundary-layer flow. This region is followed by the meandering of the vortices which takes place at $\mathrm{x} \approx 800 \mathrm{~mm}$, as depicted in Figs. 4(a)-(d). This phenomenon indicates the presence of the secondary instability mode called sinuous mode that is believed to lead the flow to turbulence [25].

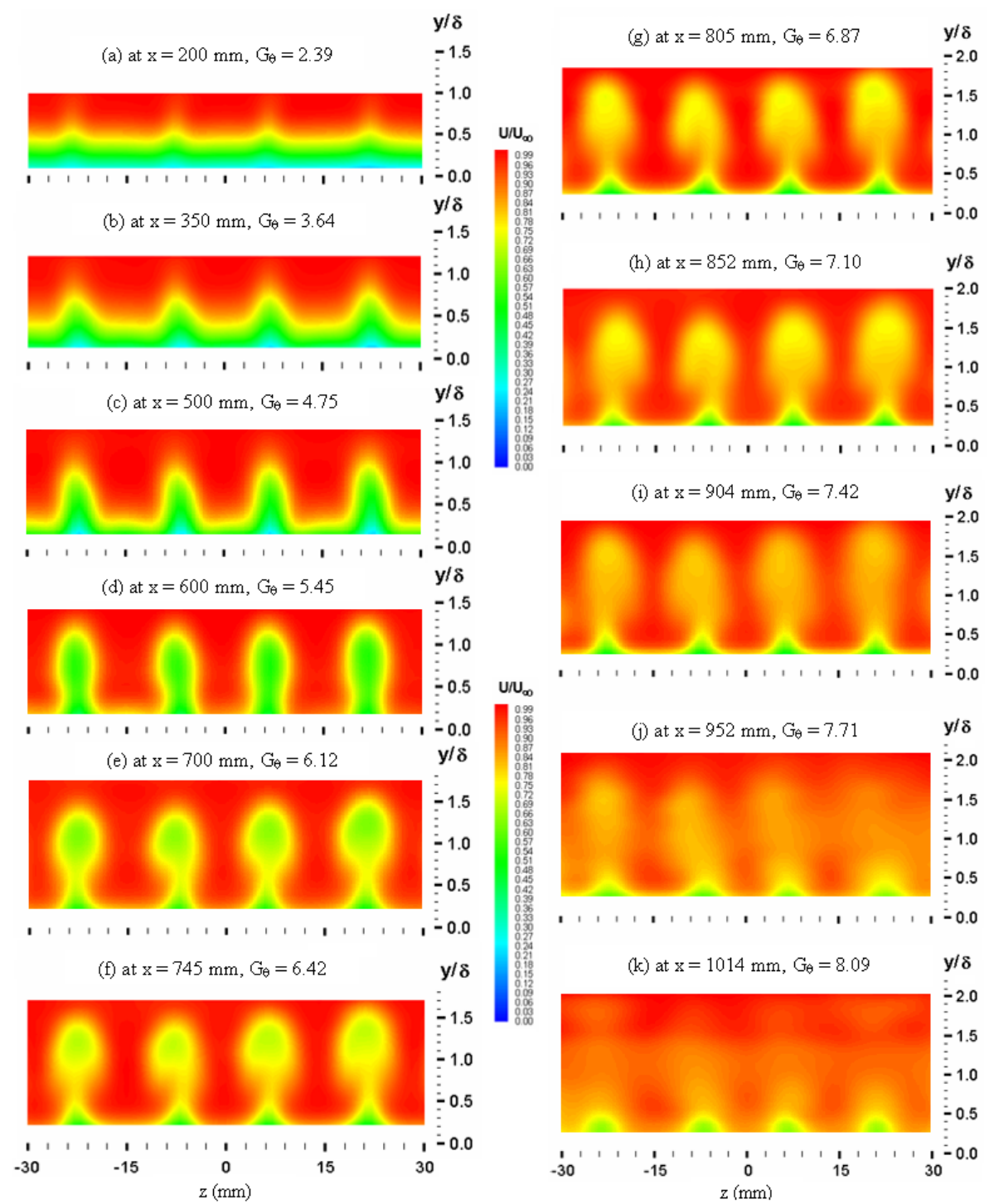

Fig. 3 Mean velocity $\left(\mathrm{U} / \mathrm{U}_{\infty}\right)$ contours on $\mathrm{y}-\mathrm{z}$ plane showing the development of Görtler vortices in boundary layer flow on concave surface of $\mathrm{R}=2 \mathrm{~m}$ for $\mathrm{U}_{\infty}=3 \mathrm{~m} / \mathrm{s}$ and wire spacing of $15.0 \mathrm{~mm}$ [26]. Note: $\delta$ is the Blasius boundary layer thickness. 
(a) At $y / \delta=0.25$

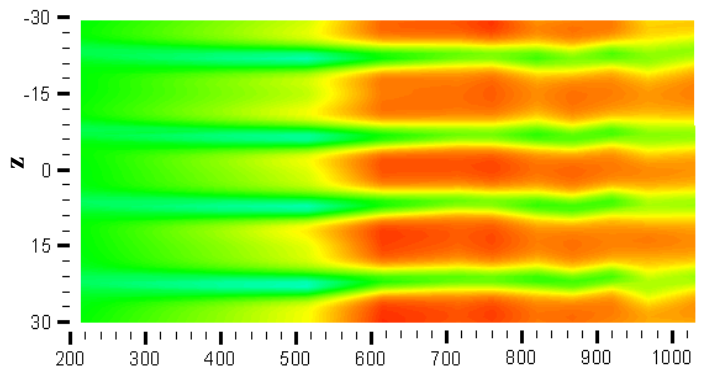

(b) At $y / \delta=0.50$

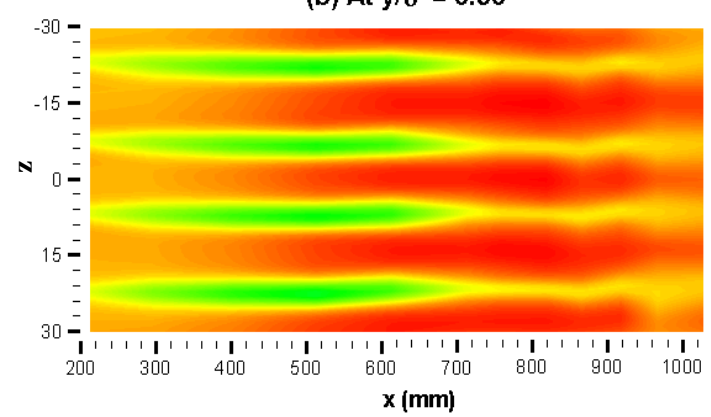

(c) At $y / \delta=0.75$

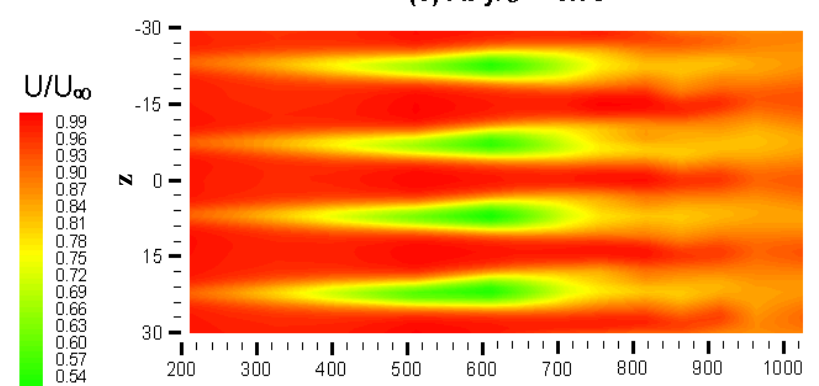

(d) At $y / \delta=1.00$

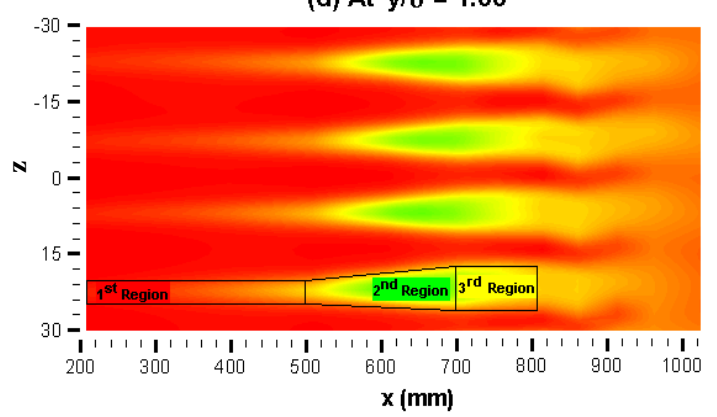

Fig. 4 Mean velocity $\left(\mathrm{U} / \mathrm{U}_{\infty}\right)$ contours on $\mathrm{x}-\mathrm{z}$ plane on concave surface of $\mathrm{R}=2 \mathrm{~m}$ at $\mathrm{U}_{\infty}=3 \mathrm{~m} / \mathrm{s}$ :

(a) at $\mathrm{y}=0.25 \delta$, (b) at $\mathrm{y}=0.50 \delta$, (c) at $\mathrm{y}=0.75 \delta$, and (d) at $\mathrm{y}=\delta$, for $15.0 \mathrm{~mm}$ wire spacing (from Winoto et al. [25]). Note: $\delta$ is the Blasius boundary layer thickness.

The streamwise disturbance amplitude $\kappa_{\mathrm{u}}(\eta)$ defined as [27]:

$$
\kappa_{\mathrm{u}}(\eta)=\frac{\left\{\mathrm{U}_{\mathrm{D}}(\eta)-\mathrm{U}_{\mathrm{U}}(\eta)\right\}}{2 \mathrm{U}_{\infty}}
$$

where $U_{D}$ is mean velocity at downwash, $U_{U}$ mean velocity at upwash and $\eta=\mathrm{y} \sqrt{U_{\infty} / x v}$ represents the dimensionless coordinate normal to the wall, was used by Finnis and Brown [13] to determine the maximum disturbance amplitude ( $\left.\kappa_{\text {umax }}\right)$ at every streamwise (x) location. Figure 5 compares the streamwise variations of $\kappa_{\text {umax }}$ for $\mathrm{R}=1 \mathrm{~m}, \mathrm{R}=2 \mathrm{~m}$, and $\mathrm{R}=4 \mathrm{~m}$ of Finnis and Brown [28] who investigated naturally developing Görtler vortices in the linear region at $\mathrm{U}_{\infty}=7.5$ and $10 \mathrm{~m} / \mathrm{s}$. While the present results $(\mathrm{R}=1 \mathrm{~m}$ and $2 \mathrm{~m})$ are of pre-set most amplified wavelength Görtler vortices. The slopes of straight lines in the semi-log chart, as shown in Fig. 5, correspond to the constant values of vortex growth rate $\beta$ assumed in the normal-mode analysis Finnis and Brown [13].

Comparison with the case for $\mathrm{R}=2 \mathrm{~m}$ in Fig $4(\mathrm{~d})$ shows that $\kappa_{\mathrm{umax}}$ in the $2^{\text {nd }}$ region increases exponentially with growth rate lower than that for the $1^{\text {st }}$ region. This could be attributed to the occurrence of the $3^{\text {rd }}$ region in which the finite amplitude of the disturbance is reached and the flow is dominated by the mushroom-like structures. This region is followed by the region where $\kappa_{\text {umax }}$ decreases exponentially which shows the saturation of the disturbance amplitude. This agrees with Schmid and Henningson [29]. However, the spectrum analysis of the fluctuating component $u^{\prime}$ shows that the secondary instabilities arise prior to the nonlinear saturation as exhibited by the formation of the peak in the spectrum with a band between 50 to $200 \mathrm{~Hz}$ at the streamwise location where the amplitude of the disturbance is still developing.

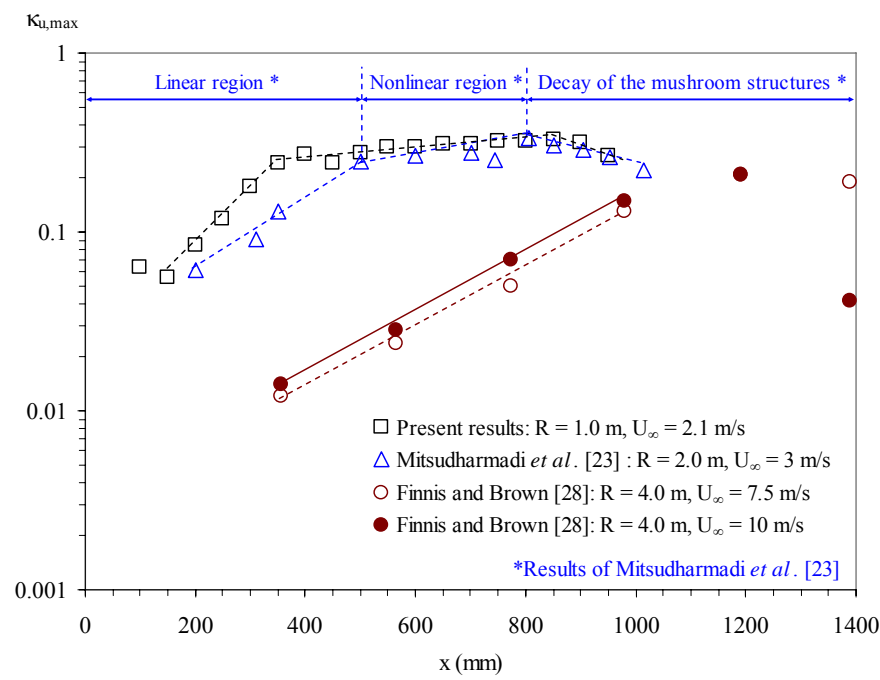

Fig. 5 Streamwise distribution of maximum disturbance amplitude showing the linear and non-linear (exponential) growth of vortices in the boundary layer flow on some concave surface radii of curvature. 


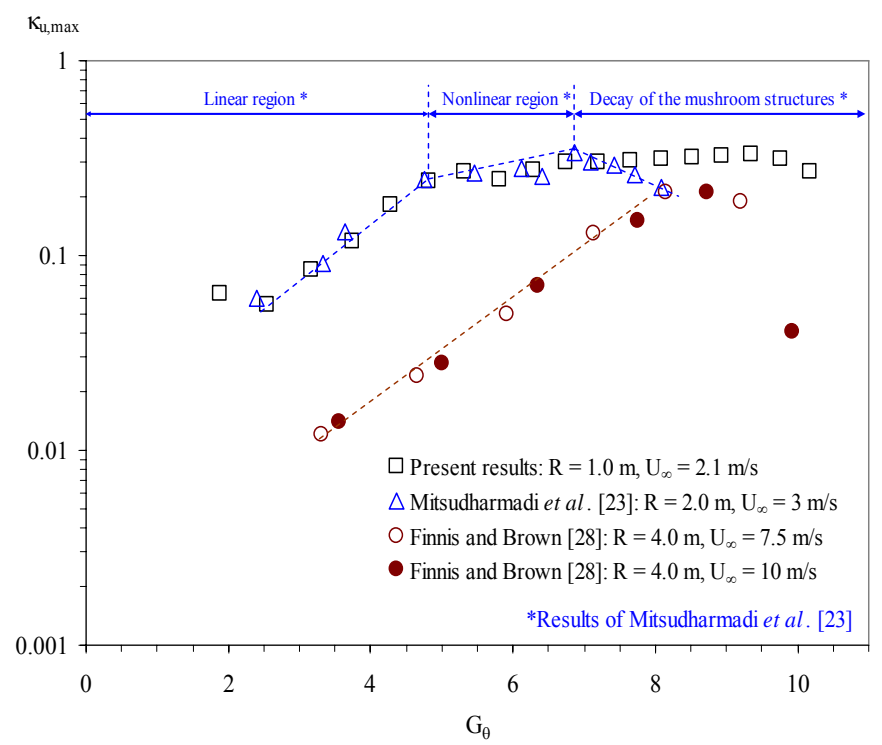

Fig. 6 Maximum disturbance amplitude against $\mathrm{G}_{\theta}$ on some different concave surfaces.

As shown in Fig. 5, the linear region for $\mathrm{R}=1 \mathrm{~m}, \mathrm{R}=2 \mathrm{~m}$, and $\mathrm{R}=4 \mathrm{~m}$ respectively range from $150-350 \mathrm{~mm}, 200-500 \mathrm{~mm}$, and 356-980 $\mathrm{mm}$. The linear region is shorter for shorter radius of curvature, as expected. The slopes obtained from the figure (which is a measure of the vortex growth rate) are respectively $7.42 \mathrm{~m}^{-1}, 4.74 \mathrm{~m}^{-1}$, and $3.71 \mathrm{~m}^{-1}$ for $\mathrm{R}=1 \mathrm{~m}, 2 \mathrm{~m}, 4 \mathrm{~m}$ at $\mathrm{U}_{\infty}=7.5$ $\mathrm{m} / \mathrm{s}$, and $3.78 \mathrm{~m}^{-1}$ for $\mathrm{R}=4 \mathrm{~m}$ at $\mathrm{U}_{\infty}=10 \mathrm{~m} / \mathrm{s}$. Based on Finnis and Brown's results [28], there is almost no significant effect of $U_{\infty}$ to the vortex growth rate as long as the radius of curvature is constant. However, the vortex growth rate increases steeper for shorter radius of curvatures.

The non-linear development of Görtler vortices on concave surfaces of $\mathrm{R}=1 \mathrm{~m}$ and $2 \mathrm{~m}$ ranges from 350-850 $\mathrm{mm}$ and 500$805 \mathrm{~mm}$, respectively. A smaller radius of curvature has a longer non-linear region than a larger one. However, the streamwise locations where the flow becomes turbulence are about the same for both cases, that is, at about $\mathrm{x} \approx 850 \mathrm{~mm}$.

By replacing $\mathrm{x}$ in Fig. 5 with $\mathrm{G}_{\theta}$, as shown in Fig. 6, all points of $\kappa_{\text {umax }}$ for pre-set wavelength Görtler vortices seem to lie on a single line. Similarly, all points of $\kappa_{\text {umax }}$ for naturally developing Görtler vortices of Finnis and Brown [28] also lie on another line. It was not clear whether this was a coincidence or whether the vortex maximum amplitudes would also lie on the same line Finnis and Brown [28]. Based on the present results, it seems that all data points of $\kappa_{\text {umax }}$ obtained from the same experimental set-up will lie on a single line, regardless of the values of $U_{\infty}$ and R. Experimental results with different wire spacings and free-stream velocities confirm this tendency.

Figure 6 shows that the onset of linear and non-linear regions for both $\mathrm{R}=1$ and $2 \mathrm{~m}$ occur at about the same $\mathrm{G}_{\theta}$ of respectively around 2.5 and 4.8. The maximum disturbance amplitude $\kappa_{\text {umax }}$ at the onset of linear and non-linear regions is also about the same, respectively at 0.058 and 0.246 . The maximum disturbance amplitude before meandering of secondary instability is about 0.32 regardless of the concave surface radius of curvature. Winoto and Crane [27] reported this value in the range of 0.3 to 0.4 .
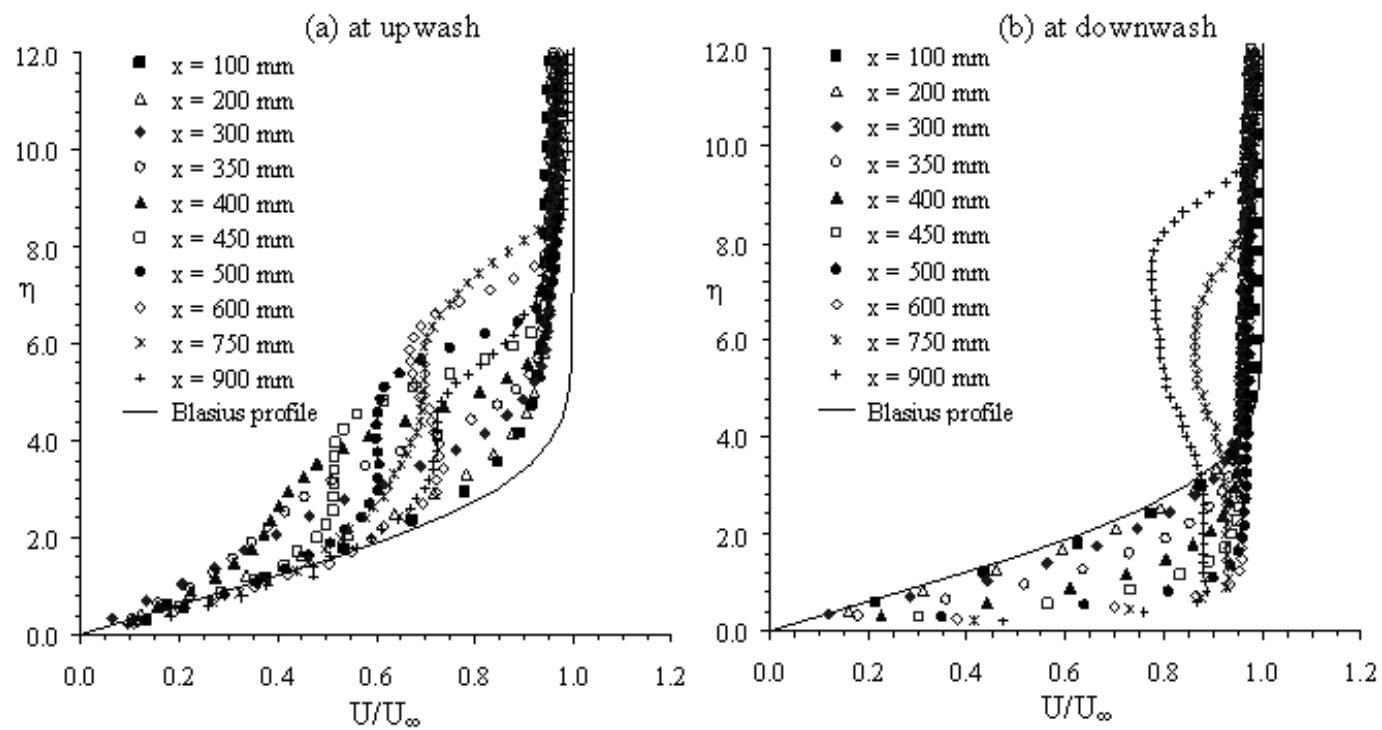

Fig. 7 Mean velocity $\left(U / U_{\infty}\right)$ profiles across boundary layers on concave surface of $R=1 \mathrm{~m}$ for $\mathrm{U}_{\infty}=2.1 \mathrm{~m} / \mathrm{s}$ at some streamwise $(\mathrm{x})$ locations. 

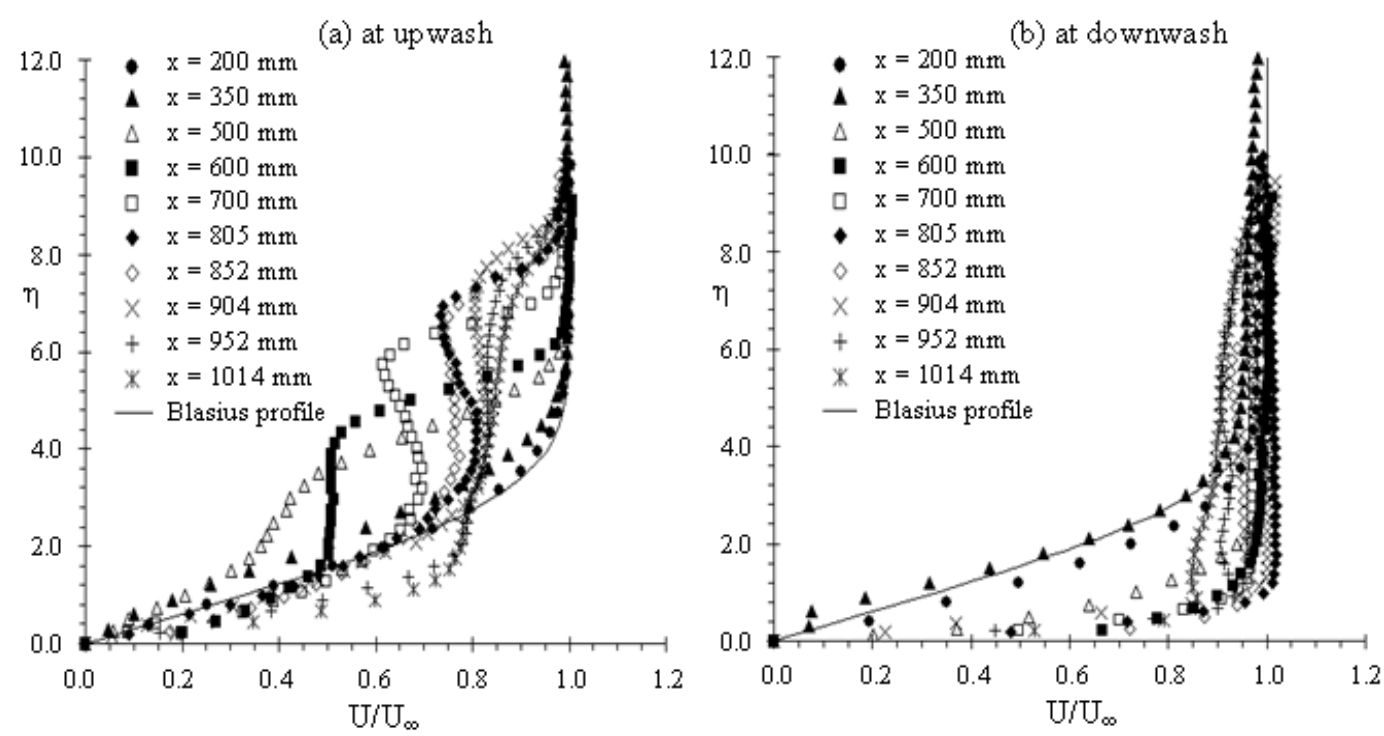

Fig. 8 Mean velocity $\left(\mathrm{U} / \mathrm{U}_{\infty}\right)$ profiles across boundary layers on concave surface of $\mathrm{R}=2 \mathrm{~m}$ for $\mathrm{U}_{\infty}=3 \mathrm{~m} / \mathrm{s}$ at some streamwise (x) locations.
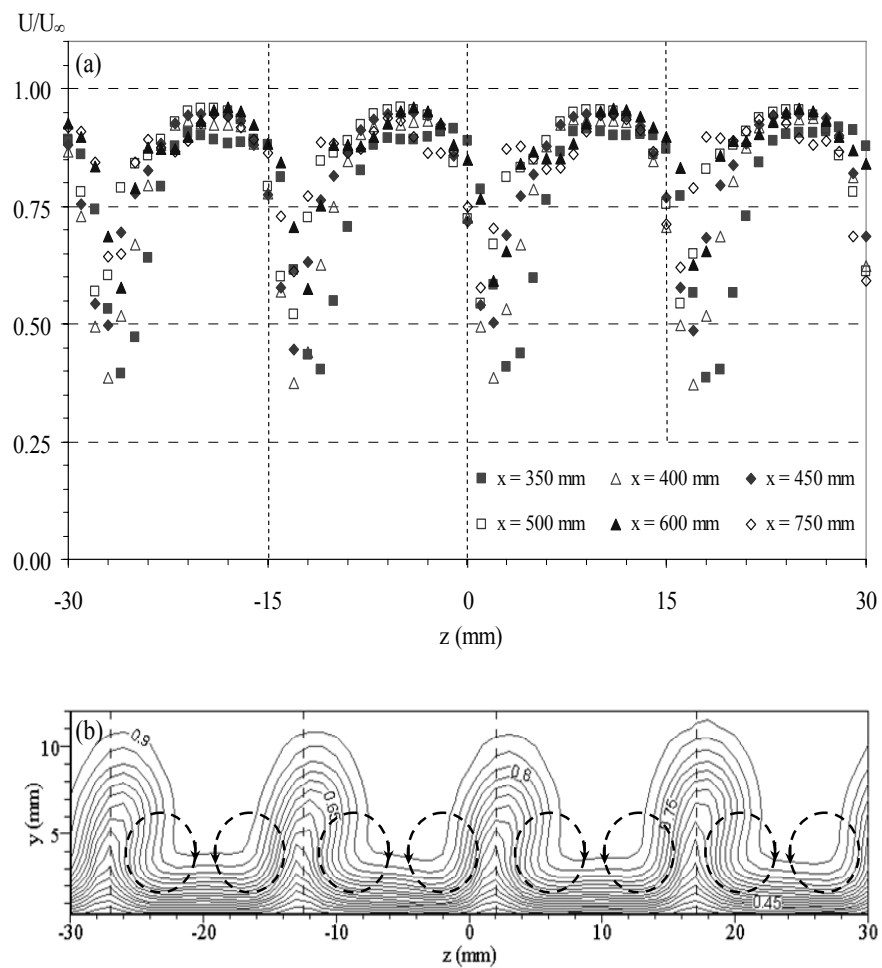

Fig. 9 Boundary layer flow on concave surface of $R=1 \mathrm{~m}$ at $U_{\infty}=2.1 \mathrm{~m} / \mathrm{s}$ : (a) Spanwise distributions of $\mathrm{U} / \mathrm{U}_{\infty}$ at $\mathrm{y} / \delta=0.5$ and $\mathrm{x}=350,400,450,500,600$ and $750 \mathrm{~mm},(\mathrm{~b}) \mathrm{U} / \mathrm{U}_{\infty}$ contour at $\mathrm{x}=400 \mathrm{~mm}\left(\mathrm{G}_{\theta}=5.31\right)$.

Alternatively, the start of non-linear region can be located by the formation of an inflection point in the boundary-layer velocity profile at upwash. The horseshoe vortices as the secondary instability of Görtler vortices are known to be caused by the high shear layer near the edge of the boundary-layer [18], which is a consequence of the formation of the inflection point in the velocity profile. The plots of $\mathrm{U} / \mathrm{U}_{\infty}$ against $\eta$ at upwash and downwash are shown in Figs. 7 and 8 for the case of $\mathrm{R}=1 \mathrm{~m}$ and $2 \mathrm{~m}$, respectively. From these figures, it is clear that the development of the velocity profiles across the boundary layer is similar. Before the Görtler vortices become "stronger", the profiles at upwash and downwash follow the Blasius profile. Farther downstream, the profiles become "thinner" at upwash and "fuller" at downwash. The inflection point subsequently appears at the upwash indicating the onset of the non-linear region at $\mathrm{x}=350 \mathrm{~mm}$ and $500 \mathrm{~mm}$ for $\mathrm{R}=1 \mathrm{~m}$ and $2 \mathrm{~m}$, respectively.

Referring to Fig. 5, the larger amplitude of the disturbances in the non-linear region will lead to point of inflection in the upwash velocity profiles as shown in Figs. 7(a) and 8(a). This agrees well with the results of Wortmann [30], Aihara and Koyama [31], and Swearingen and Blackwelder [32]. 


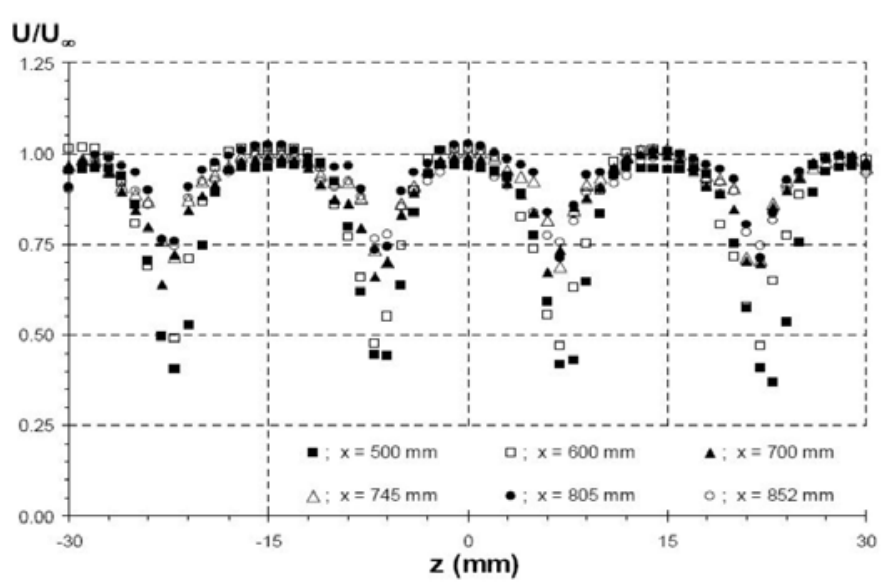

(a)

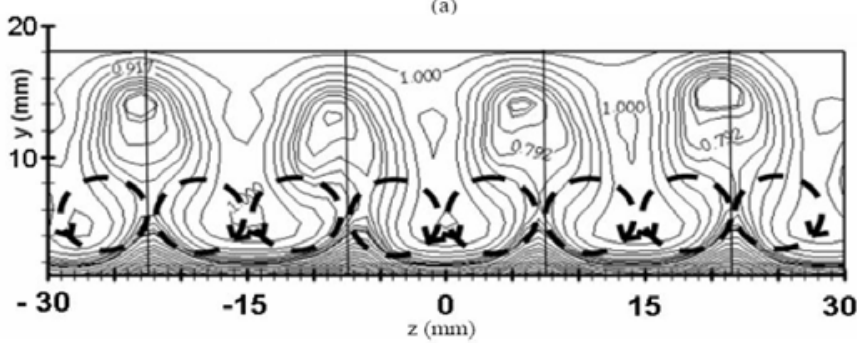

(b)

Fig. 10 Boundary layer flow on concave surface of $R=2 \mathrm{~m}$ at $U_{\infty}=3 \mathrm{~m} / \mathrm{s}$ [23]: (a) Spanwise distributions of $U / \mathrm{U}_{\infty}$ at $\mathrm{y} / \delta=0.5$ and $\mathrm{x}=500,600,700,745,805$ and $852 \mathrm{~mm},(\mathrm{~b}) \mathrm{U} / \mathrm{U}_{\infty}$ contour at $\mathrm{x}=805 \mathrm{~mm}\left(\mathrm{G}_{\theta}=6.87\right)$.

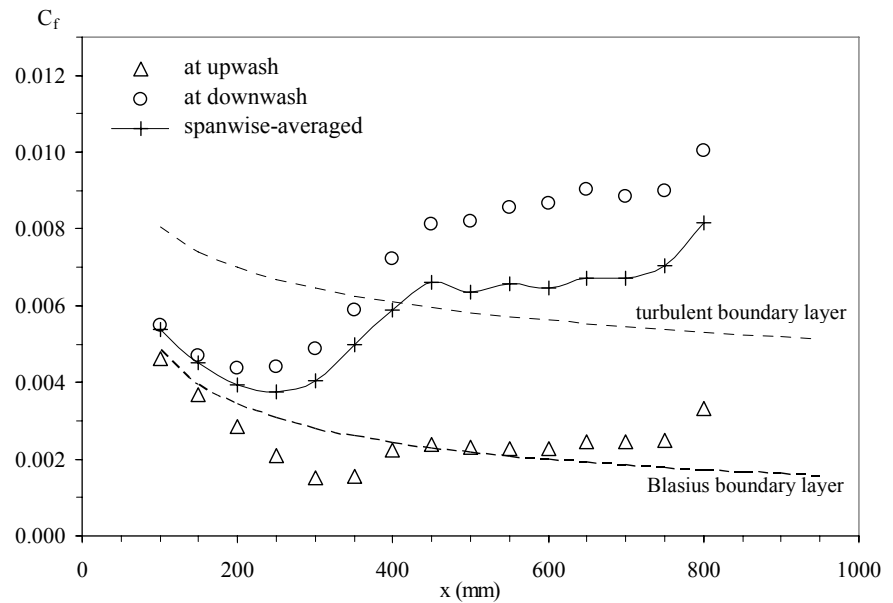

Fig. 11 Streamwise development of wall shear stress coefficient $\mathrm{C}_{\mathrm{f}}\left(=\tau_{\mathrm{w}} / 0.5 \rho \mathrm{U}_{\infty}{ }^{2}\right)$ at upwash, downwash, and spanwise-averaged on concave surface of $\mathrm{R}=1 \mathrm{~m}$ for $\mathrm{U}_{\infty}=2.1 \mathrm{~m} / \mathrm{s}$ and $\lambda_{\mathrm{m}}=12 \mathrm{~mm}$.

Associated with the non-linear growth region of Görtler vortices, the spanwise variation of the streamwise velocity becomes flattened at the high velocity (downwash) region, and narrow and sharp at the low velocity (upwash) region [31] as shown in Figs. 9 (a) and 10 (a) at $\mathrm{y} \approx 0.5 \delta$ (where $\delta$ is the Blasius boundary-layer thickness) for some streamwise (x) locations in the non-linear region. These phenomena give rise to the transformation of the horseshoe structures into the mushroom-like structures observed in the velocity contours. Figures 9 (b) and 10(b) show the horseshoe and mushroom-like structures at $\mathrm{x}=400 \mathrm{~mm}$ for $\mathrm{R}=1 \mathrm{~m}$ and at $\mathrm{x}=805 \mathrm{~mm}$ for $\mathrm{R}=2 \mathrm{~m}$ (the circles indicate the directions of movement of fluid particles in the streamwise counter-rotating vortices). Despite the inflectional points at the velocity profiles across the boundary layer, the spanwise distribution of the velocity is also inflected further downstream. Furthermore, the inflectional points at normal and spanwise directions are associated with the most unstable even and odd modes of secondary instability, respectively [33].

Computations [34-36] showed increasing wall shear stress $\tau_{\mathrm{w}}$ in concave surface boundary layer flow as the effect of nonlinear development of Gortler instability. The present study reveals this phenomenon, as shown in Fig. 11. The spanwise-averaged wall shear stress, which initially decreases following the Blasius curve, starts to increase at $x=300 \mathrm{~mm}$ and increases further well beyond the flat plate turbulent boundary layer values. At downwash region, the wall shear stress initially decreases at the rate slightly lower than the Blasius curve, but at $x=250 \mathrm{~mm}$ it starts to increase significantly downstream until $\mathrm{x}=450 \mathrm{~mm}$. At the upwash region, the wall shear stress decreases faster than the Blasius curve until $x=300 \mathrm{~mm}$. After reaching its minimum point, it increases to reach the Blasius curve and follows it closely until the transition to turbulence at $\mathrm{x}=750 \mathrm{~mm}$ [37]. 


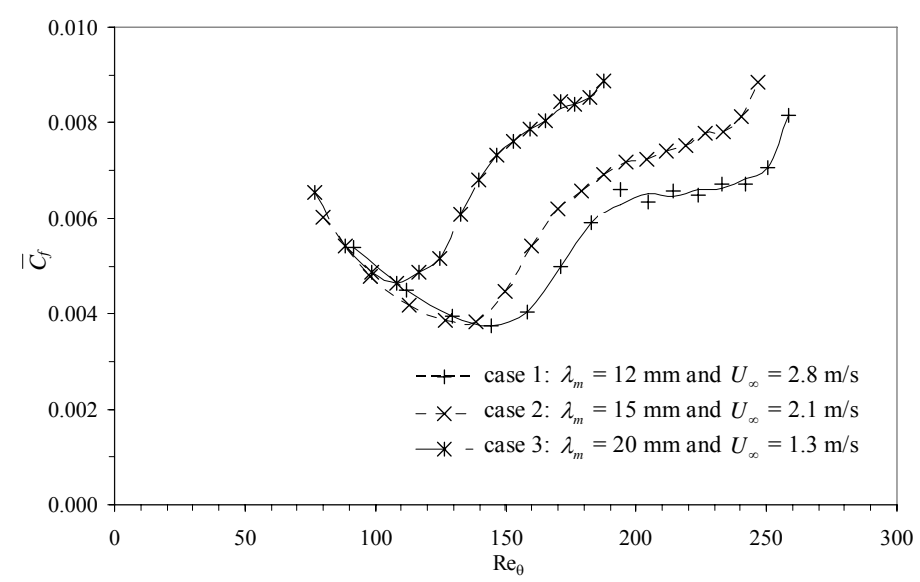

Fig. 12 Spanwise-averaged wall shear stress coefficient $\bar{C}_{f}$ versus Reynolds number $\operatorname{Re}_{\theta}$ for case $1: \lambda_{\mathrm{m}}=12 \mathrm{~mm}$ and $\mathrm{U}_{\infty}=2.8$ $\mathrm{m} / \mathrm{s}$, case $2: \lambda_{\mathrm{m}}=15 \mathrm{~mm}$ and $\mathrm{U}_{\infty}=2.1 \mathrm{~m} / \mathrm{s}$, and case $3: \lambda_{\mathrm{m}}=20 \mathrm{~mm}$ and $\mathrm{U}_{\infty}=1.3 \mathrm{~m} / \mathrm{s}$.
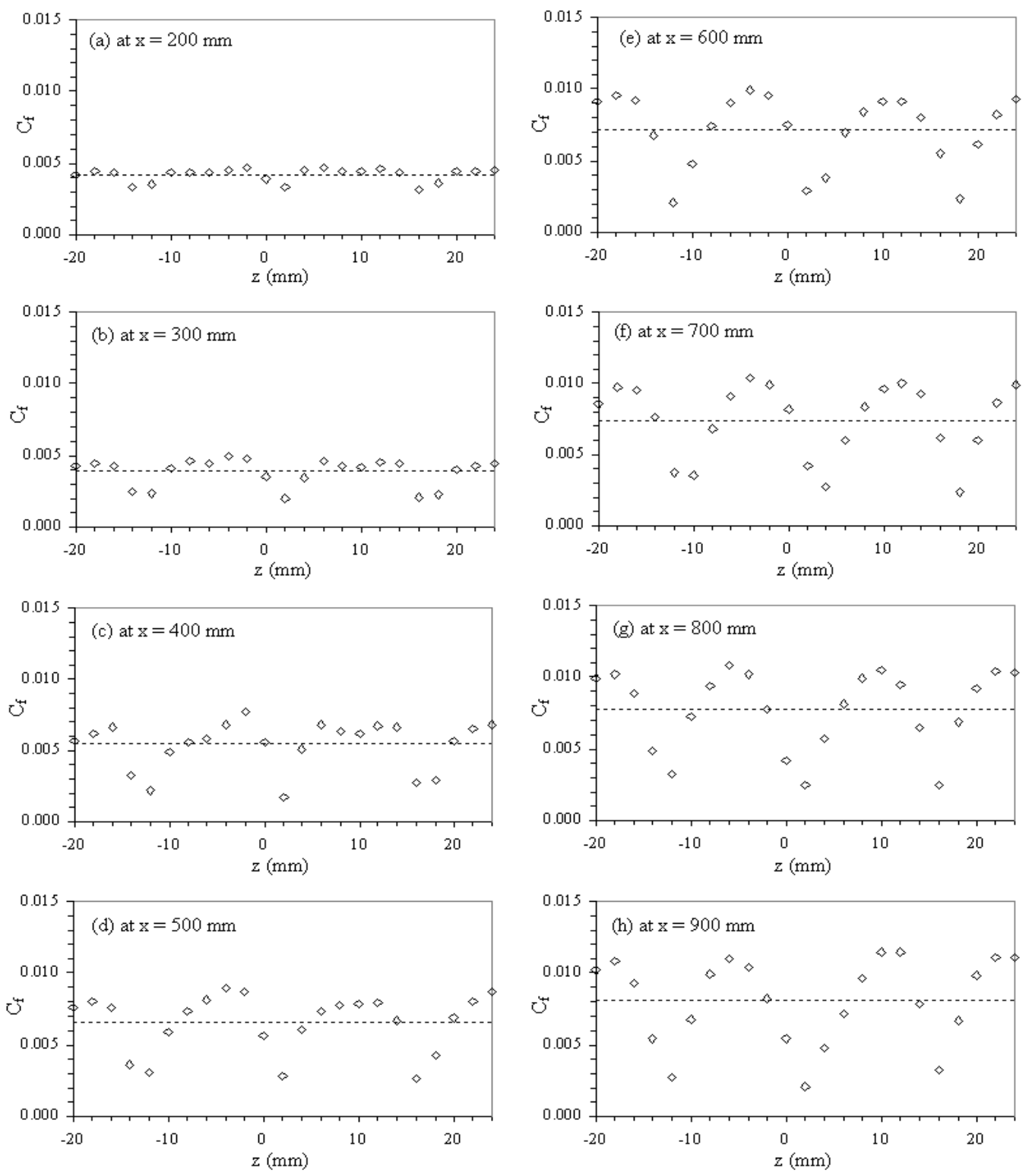

Fig. 13 Spanwise distributions of wall shear stress coefficient $C_{f}$ for $\lambda_{m}=15 \mathrm{~mm}$ and $U_{\infty}=2.1 \mathrm{~m} / \mathrm{s}$ (---- is spanwise-averaged value $\bar{C}_{f}$ at the streamwise position).

The streamwise developments of the spanwise-averaged $\tau_{\mathrm{w}}$ for all the three cases are shown in Fig. 12, presented as spanwiseaveraged wall shear stress coefficient $\bar{C}_{f}$ and the streamwise (x) distance as Reynolds number $\operatorname{Re}_{\theta}\left(=\mathrm{U}_{\infty} \theta / v\right)$, where $\theta$ is the Blasius boundary layer momentum thickness. The figure shows the same development of $\bar{C}_{f}$ for all cases, where it first decreases 
and then increases further downstream. Before reaching their minima, $\bar{C}_{f}$ for all cases seems to follow the same line. The values of $\operatorname{Re}_{\theta}$ at the minima are respectively 150,140 , and 110 for case $1\left(\lambda_{\mathrm{m}}=12 \mathrm{~mm}\right)$, case $2\left(\lambda_{\mathrm{m}}=15 \mathrm{~mm}\right)$, and case $3\left(\lambda_{\mathrm{m}}=20 \mathrm{~mm}\right)$. These locations correspond to the same Görtler number $\mathrm{G}_{\theta} \approx 4$.0. After their minimum points, the $\bar{C}_{f}$ curves increase significantly downstream until $\operatorname{Re}_{\theta}$ of 180,170 , and 140 for case 1,2 , and 3 , respectively. These values of $\operatorname{Re}_{\theta}$ also correspond to the same Gortler number $\mathrm{G}_{\theta} \approx 6.0$. This significant increase is due to the nonlinear effect and the appearance of secondary instability. Then farther downstream, the increasing rate of $\bar{C}_{f}$ reduces for a finite range of $\operatorname{Re}_{\theta}$ before a substantial increase occurs again as a result of increased mixing due to the onset of flow transition to turbulence.

As shown in Fig. 12, the minimum wall shear stress $\bar{C}_{f}$ of larger vortices occurs at lower $\operatorname{Re}_{\theta}$. After reaching their minima, larger vortices consistently produce higher wall shear stress at any value of $\operatorname{Re}_{\theta}$. These may be due to the fact that larger vortices are more "vigorous" [38]. In addition, Görtler vortex wavelength also has a direct influence to the type of the secondary instability mode, which of course will affect the development of the wall shear stress [33].

The spanwise distributions of $\tau_{\mathrm{w}}$ in term of $\mathrm{C}_{\mathrm{f}}$ for several streamwise positions are presented in Fig. 13, where the broken-line is the spanwise-averaged value $\bar{C}_{f}$ at the corresponding streamwise position. Initially, the $\mathrm{C}_{\mathrm{f}}$ spanwise distribution seems to correlate with the spanwise distribution of $\mathrm{U} / \mathrm{U}_{\infty}$. However, farther downstream, the spanwise distributions of $\mathrm{C}_{\mathrm{f}}$ do not become flat at downwash and narrow at upwash, as shown in the spanwise distributions of $U / U_{\infty}$ in Figs. 9 and 10. Instead, the $C_{f}$ distributions at downwash regions become narrower, and there is no inflection point found in the distributions. This may be because the sinuous mode of secondary instability, which is initiated near the boundary layer edge, is not strong enough to alter the distribution of the wall shear stress. This also explains why the increasing rate of $\mathrm{C}_{\mathrm{f}}$ (in Figs. 11 and 12) reduces significantly prior to flow transition to turbulence. The main contribution to the $\tau_{\mathrm{w}}$ enhancement in a concave surface boundary layer flow may be attributed to the varicose mode of the secondary instability. This is concluded from the fact that the waviness in $\mathrm{C}_{\mathrm{f}}$ distribution becomes more pronounced and the spanwise-averaged value $\bar{C}_{f}$ increases significantly at the early stage of the nonlinear region where the flow instability, in the present work, is dominated by the varicose mode.
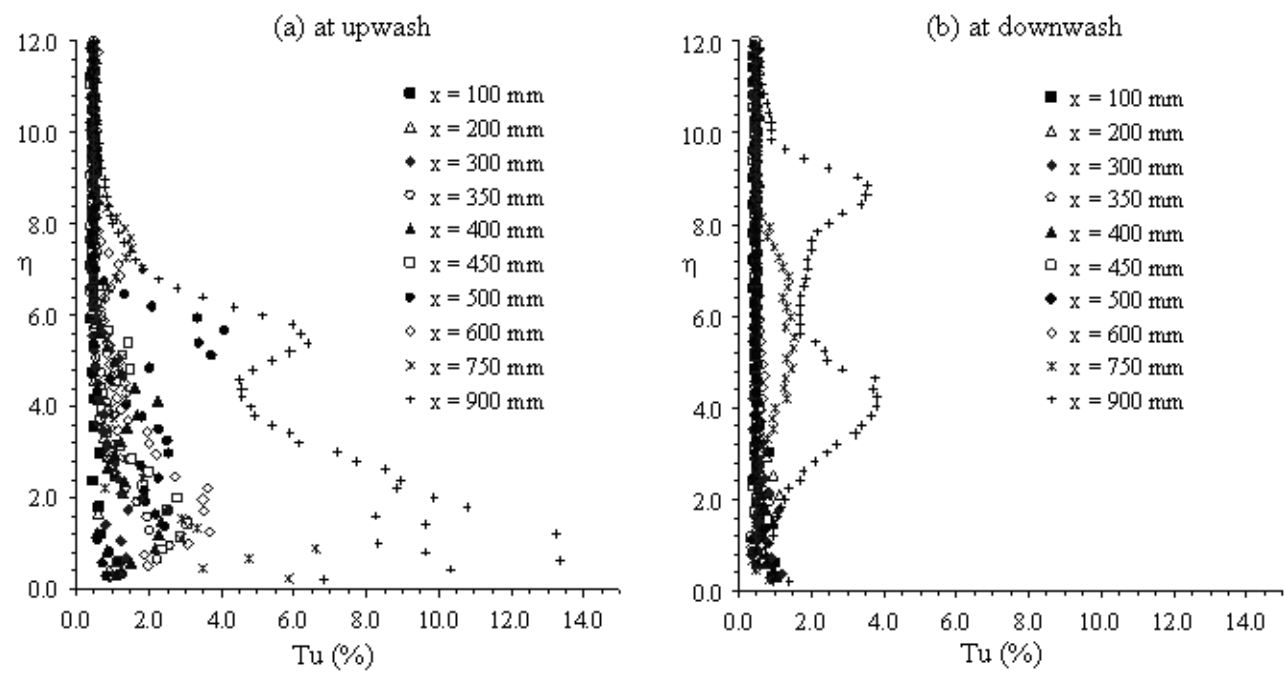

Fig. 14 Distribution of turbulent intensity $(\mathrm{Tu})$ across boundary layers on concave surface of $\mathrm{R}=1 \mathrm{~m}$ for $\mathrm{U}_{\infty}=2.1 \mathrm{~m} / \mathrm{s}$ at some streamwise $(\mathrm{x})$ locations.
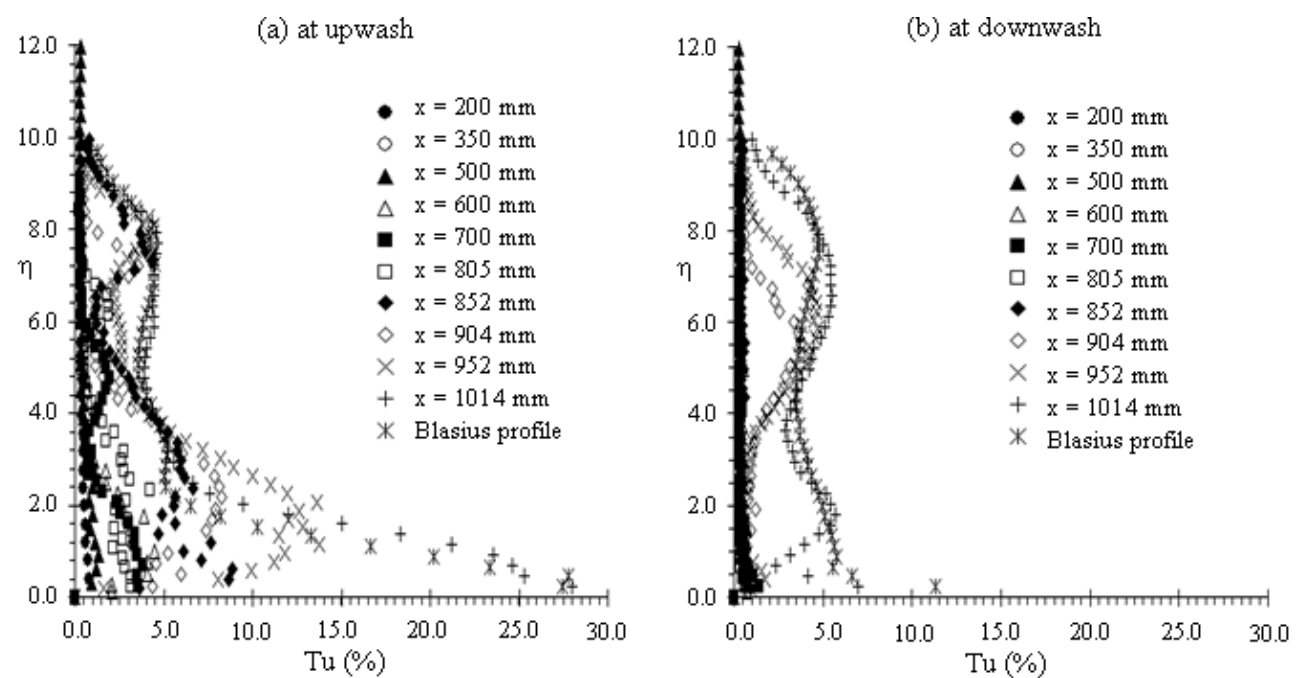

Fig. 15 Distribution of turbulent intensity (Tu) across boundary layers on concave surface of $R=2 \mathrm{~m}$ for $U_{\infty}=3 \mathrm{~m} / \mathrm{s}$ at some streamwise (x) locations. 
The high shear layer near the boundary-layer edge causes the formation of the second peak in the turbulence intensity (Tu) profile at the upwash region which was first observed at $\mathrm{x}=350 \mathrm{~mm}$ and $500 \mathrm{~mm}$ for $\mathrm{R}=1 \mathrm{~m}$ and $2 \mathrm{~m}$ respectively, as shown in Fig. 14(a) and 15(a). The formation of high shear layer initiates the development of horseshoe vortices as the initiation of the secondary instability [18]. As these horseshoe vortices propagate downstream and breakdown, the turbulence spreads out in the boundary-layer resulting in the decay of the second peak near the boundary-layer edge until the turbulence near the wall becomes dominant in the flow. The decay process of the second peak is related to the breakdown of vortex structure in the boundary-layer.

The turbulence intensities at upwash are much higher than at downwash, implying that upwash region is the most unstable region in the boundary layer. Note that the turbulence intensities for $\mathrm{R}=1 \mathrm{~m}$ (Fig. 14) are lower than those for $\mathrm{R}=2 \mathrm{~m}$ (Fig. 15). This might be due to lower free-stream velocity for the case of $\mathrm{R}=1 \mathrm{~m}$.
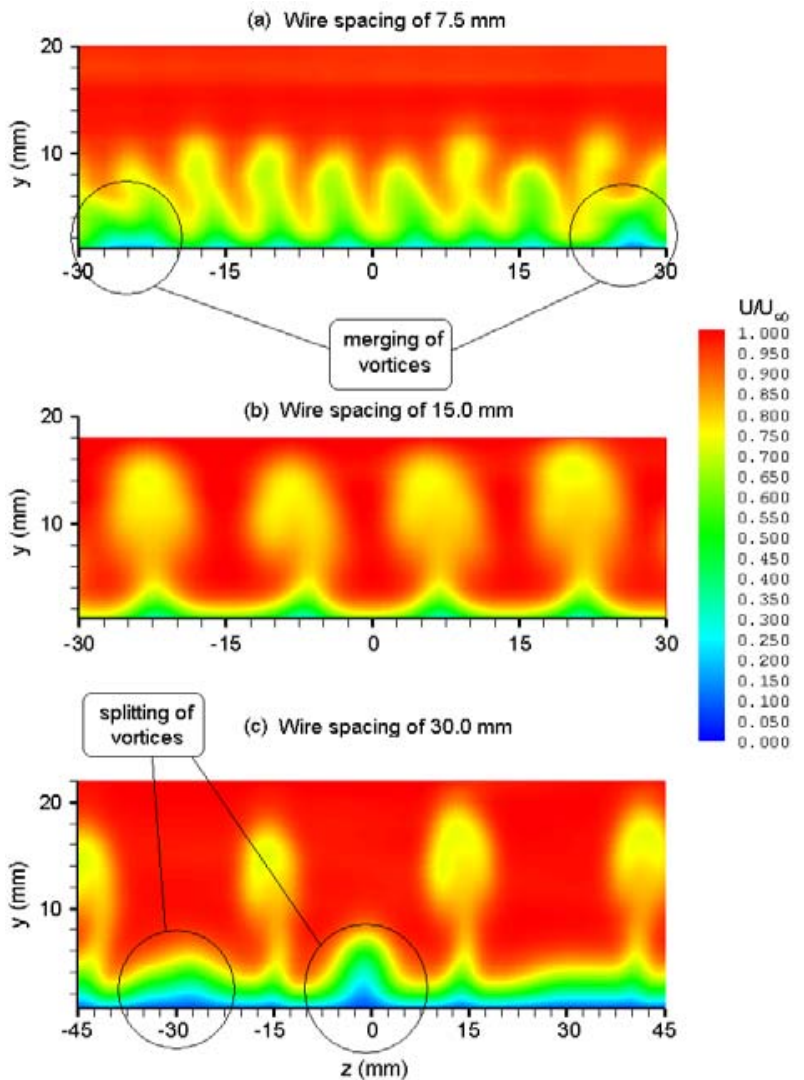

Fig. 16 Comparison of mean velocity $\left(U / U_{\infty}\right)$ contours at $x=700 \mathrm{~mm}\left(\mathrm{G}_{\theta}=6.87\right)$ and $\mathrm{U}_{\infty}=3.0 \mathrm{~m} / \mathrm{s}$ for wire spacings of

(a) $7.5 \mathrm{~mm}$, (b) $15.0 \mathrm{~mm}$, and (c) $30.0 \mathrm{~mm}$ (from Winoto et al. [40]).

The development of Görtler vortices in concave surface boundary layer flow is dominated by the most amplified vortex wavelength which can be predicted by the wavelength parameter $\Lambda$ in the range of 200-270. When $\Lambda$ is much lower or greater than the values in the range, splitting and merging of Görtler vortices will occur in the non-linear region. These processes are shown in Fig. 16 by the mean velocity contours at $\mathrm{x}=700 \mathrm{~mm}$ for $\mathrm{R}=2 \mathrm{~m}$. The merging of two mushroom-like structures in the spanwise locations $\mathrm{z}$ of about $-25 \mathrm{~mm}$ and $27 \mathrm{~mm}$ is shown in Fig. 16(a) and the formation of the secondary mushroom-like structure in the middle of the wire spacing indicating the splitting of the vortices is shown in Fig. 16(c). These findings agree with Guo and Finlay [39] who computationally found that spatially developing Dean and Görtler vortices to be most unstable to spanwise disturbance with wavelength twice or 1.5 times of the dominant wavelength. Accordingly, due to the nonlinear growth of these perturbations, a small vortex pair is generated in-between two pairs of long wavelength vortices, but it forces two pairs of vortices with short wavelength to develop into one pair.

The pre-set vortex wavelength of $15 \mathrm{~mm}$ (for which $\Lambda=249$ ) is maintained downstream until the breakdown of the mushroom-like structures prior to turbulence. This is in contrast with the naturally developed Görtler vortices.

In the Görtler vortex stability diagram of $\mathrm{G}_{\theta}$ versus $\alpha \theta$ (where $\alpha=2 \pi / \lambda$ ) of Smith [2] shown in Fig. 17, the present results are well inside the unstable region. The wavelength parameter $\Lambda$ as defined by Eq. (2), represents a family of straight lines on the stability diagram, which can be used to predict the wavelength of naturally developing Görtler vortices. The lines $\Lambda=88$ and 732 in the diagram represent the development of pre-set wavelength Görtler vortices for wire spacing of $7.5 \mathrm{~mm}$ and $30 \mathrm{~mm}$ respectively for $\mathrm{U}_{\infty}=3 \mathrm{~m} / \mathrm{s}$ and $\mathrm{R}=2 \mathrm{~m}$. The results show that in the linear region, these pre-set vortex wavelengths are maintained. The merging and splitting of the vortices start after the linear region, and the vortex developments according to the lines $\Lambda=88$ and 732 will then "switch" to the line $\Lambda=249$. These confirm that $\lambda=15 \mathrm{~mm}$ (for which $\Lambda=249$ ) is the most amplified vortex wavelength that will be maintained downstream prior to turbulence for boundary layer on concave surface of $\mathrm{R}=$ $2 \mathrm{~m}$ for $\mathrm{U}_{\infty}=3 \mathrm{~m} / \mathrm{s}$, as reported earlier by Mitsudharmadi et al. [23]. The present case of $\lambda=15 \mathrm{~mm}$ for $\mathrm{R}=1 \mathrm{~m}$ and $\mathrm{U}_{\infty}=2.1 \mathrm{~m} / \mathrm{s}$ also corresponds to the most amplified wavelength with $\Lambda=252$, and the development of the vortices is similar to those reported by Mitsudharmadi et al. [23]. 


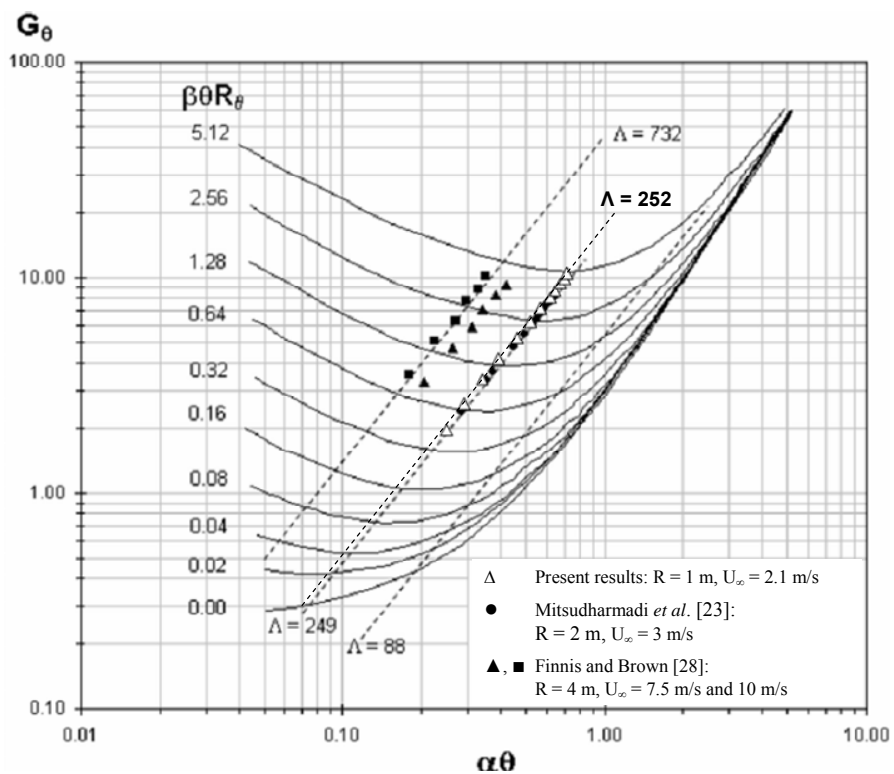

Fig. 17 Some experimental results in Görtler vortex stability diagram of Smith [2].

\section{Conclusion}

From the hot-wire data, the flow fields of pre-set wavelength Görtler vortices are visualized. The vortices were amplified dowstream until the start of boundary layer transition where $G_{\theta}=G_{\theta t r}$ [23]. This study provides more information on the instability in concave surface boundary layers. The pre-set vortex wavelength is found to equal the spanwise spacing of the vertical wires in the streamwise direction until the vortices breakdown prior to turbulence when the wavelength parameter $\Lambda$ was set in the range of 200 to 270 .

The $\mathrm{U} / \mathrm{U}_{\infty}$ contours for $15 \mathrm{~mm}$ wire spacing on the $\mathrm{x}-\mathrm{z}$ and $\mathrm{y}-\mathrm{z}$ planes show that the spanwise modulation of streamwise velocity $\mathrm{U}$, which indicates the vortex wavelength, is equal to the spanwise spacing of the wires. The velocity contours in the $y-z$ plane show the non-linear region of the vortices where the boundary-layer is dominated by the mushroom-like structures that have reached finite amplitude. This region is followed by the meandering of the vortices which indicates the presence of sinuous mode secondary instability that rapidly leads the flow to turbulence.

The streamwise variations of maximum disturbance amplitude $\kappa_{\text {umax }}$ for different concave surfaces show that shorter radius of curvature results in higher growth rate in the linear region and lower growth rate in the non-linear region. If $\kappa_{\text {umax }}$ is plotted against $\mathrm{G}_{\theta}$, all the data from the same experimental set-up follow a single line, and the onset of linear and non-linear regions for pre-set wavelength Görtler vortices occur nearly at the same points.

Measurements of wall shear stress on concave surface of $\mathrm{R}=1 \mathrm{~m}$ reveal that the spanwise-averaged wall shear stress increases well beyond the flat plate boundary layer values.

The appearance of the second peak near the boundary-layer edge in the turbulence intensity profiles at the upwash shows the formation of high shear layer near the boundary-layer edge. As the turbulence spreads into the boundary-layer, the second peak decays, which coincides with the breakdown of the vortex structure in the boundary-layer.

The effect of wire spacing to the pre-set wavelength Görtler vortices shows the splitting and merging of the vortices.

\section{Nomenclature}

$\begin{array}{ll}\mathrm{d} & \text { Vertical wire diameter [m] } \\ \mathrm{G}_{\theta} & \text { Görtler number } \\ \mathrm{G}_{\theta, \mathrm{cr}} & \text { Critical Görtler number } \\ \mathrm{G}_{\theta \mathrm{tr}} & \text { Transitional Görtler number } \\ \mathrm{C}_{\mathrm{f}} & \text { Wall shear stress coefficient }\left(=\tau_{\mathrm{w}} /\left(0.5 \rho \mathrm{U}_{\infty}{ }^{2}\right)\right. \\ \bar{C}_{f} & \text { Spanwise average wall shear stress coefficient } \\ \mathrm{R} & \text { Radius of curvature }[\mathrm{m}] \\ \mathrm{Re}_{\mathrm{d}} & \text { Reynolds number based on wire diameter }\left(\equiv \mathrm{U}_{\infty} \mathrm{d} / \mathrm{v}\right) \\ \mathrm{Re}_{\theta} & \text { Reynolds number based on Blasius boundary layer } \\ & \text { momentum thickness }\left(\equiv \mathrm{U}_{\infty} \theta / \mathrm{v}\right) \\ \mathrm{Tu} & \text { Turbulence intensity } \\ \mathrm{U} & \text { Streamwise mean velocity }[\mathrm{m} / \mathrm{s}] \\ \mathrm{U}_{\infty} & \text { Free-stream velocity [m/s] } \\ \mathrm{U}_{\mathrm{U}} & \text { Streamwise mean velocity at upwash }[\mathrm{m} / \mathrm{s}] \\ \mathrm{U}_{\mathrm{D}} & \text { Streamwise mean velocity at downwash }[\mathrm{m} / \mathrm{s}] \\ \mathrm{x} & \text { Streamwise coordinate }[\mathrm{m}]\end{array}$

$\mathrm{y}$
$\mathrm{z}$
$\alpha$
$\alpha \theta$
$\beta$
$\delta$
$\eta$
$\theta$
$\kappa_{\mathrm{u}}$
$\kappa_{\mathrm{umax}}$
$\lambda$
$\lambda_{\mathrm{m}}$
$\Lambda$
$\mathrm{v}$
$\tau_{\mathrm{w}}$

Normal coordinate $[\mathrm{m}]$

Spanwise coordinate $[\mathrm{m}]$

Wave number $(\equiv 2 \pi / \lambda)\left[\mathrm{m}^{-1}\right]$

Dimensionless wave number

Vortex growth rate $\left[\mathrm{m}^{-1}\right]$

Blasius boundary layer thickness [m]

Dimensionless normal coordinate $\left(\equiv \mathrm{y}\left(\mathrm{U}_{\infty} / \mathrm{x} v\right)^{1 / 2}\right)$

Blasius boundary layer momentum thickness [m]

Disturbance amplitude

Maximum disturbance amplitude

Vortex wavelength [m]

The most amplified vortex wavelength [m]

Non-dimensional wavelength parameter

Fluid kinematic viscosity $\left[\mathrm{m}^{2} / \mathrm{s}\right.$ ]

Wall shear stress $\left[\mathrm{N} / \mathrm{m}^{2}\right]$ 


\section{References}

[1] Görtler, H., 1940, Über eine dreidimensionale Instabilität laminarer Grenzschichten an konkaven Wänden, Ges. D. Wiss. Göttingen, Nachr. a. d., Math., Vol. 2 No. 1; translated as "On the three-dimensional instability of laminar boundary layers on concave walls", NACA TM 1375, 1954.

[2] Smith, A.M.O., 1955, "On the growth of Taylor-Görtler vortices along highly concave wall,” Quart. Appl. Mech., Vol. 13, pp. 233-262.

[3] Mitsudharmadi, H., Tay, C. M. J. and Tsai, H. M., 2007, "Visualizing the flow inside the smooth edge shallow dimple," Proc. $9^{\text {th }}$ Asian Symposium on Visualization, Hong Kong, 4 - 8 June 2007, Paper No. ASV 0217-001.

[4] Syred, N., Khalatov, A., Kozlov, A., Shchukin, A., and Agachev, R., 2001, "Effect of surface curvature on heat transfer and hydrodynamics within a single hemispherical dimple," ASME J. of Turbomachinery, Vol. 123, No. 3, pp. 609-613.

[5] Winoto, S.H., Mitsudharmadi, H. and Shah, D.A., 2005, "Visualization of pre-set wavelength Görtler vortices," Proc. $8^{\text {th }}$ Asian Symposium on Visualization, Chiangmai, Thailand, 23 - 27 May 2005, Paper No. KN8.

[6] McCormack, P.D., Welker, H. and Kelleher, M., 1970, “Taylor-Görtler vortices and their effect on heat transfer," ASME J. of Heat Transfer, Vol. 92, pp. 101-112.

[7] Kan, S., Miwa, K., Morishita, T., Munakata, Y. and Nomura, M., 1971, “Heat transfer of a turbine blade,” Proc. Joint Int. Gas Turbine Conf., Tokyo, Japan, 4-7 October 1971, pp. 219-226.

[8] Crane, R.I. and Sabzvari, J., 1989, "Heat transfer visualization and measurement in unstable concave-wall boundary layers," ASME J. of Turbomachinery, Vol. 111, pp. 51-56.

[9] Crane, R.I. and Umur, H., 1990, "Concave-wall laminar heat transfer and Görtler vortex structure: Effects of pre-curvature boundary layer and favourable pressure gradients," ASME, Paper No. 90-GT-94.

[10] Momayez, L., Dupont, P. and Peerhossaini, H., 2004, "Some unexpected effects of wavelength and perturbation strength on heat transfer enhancement by Görtler instability," Int. J. of Heat and Mass Transfer, Vol. 47, pp. 3783-3795.

[11] Momayez, L., Dupont, P. and Peerhossaini, H., 2004, "Effects of vortex organization on heat transfer enhancement by Görtler instability," Int. J. of Thermal Sciences, Vol. 43, pp. 753-760.

[12] Floryan, J.M. and Saric, W.S., 1982, "Stability of Gortler vortices in boundary layers," AIAA J., Vol. 20, No. 3, pp. $316-324$.

[13] Finnis, M.V. and Brown, A., 1989, "Stability of a laminar boundary-layer flowing along a concave surface," ASME J. of Turbomachinery, Vol. 111, pp. 376-386.

[14] Kottke, V and Mpouradis, B, 1987, “On the existence of Taylor-Görtler vortices on concave walls," Proc. $4^{\text {th }}$ Int. Symp. Flow Visualization, Paris, 1986, pp. 475-480, Hemisphere Publishing Corp., Washington.

[15] Denier, J.P., Hall, P., and Seddougui, S.O., 1991, “On the receptivity problem for Görtler vortices: vortex motions induced by wall roughness," Philosophical Transactions: Physical Sciences and Engineering, Vol. 335, No. 1636, pp. 51-85.

[16] Bassom, A.P. and Hall, P., 1994, “The receptivity problem for O(1) wavelength Görtler vortices," Proceedings: Mathematical and Physical Sciences, Vol. 446, No. 1928, pp. 499-516.

[17] Luchini, P. and Bottaro, A, 1998, "Görtler vortices: a backward-in-time approach to the receptivity problem," J. of Fluid Mechanics, Vol. 363, pp. 1-23.

[18] Floryan, J.M., 1991, "On the Görtler instability of boundary-layer," Progress in Aerospace Science, Vol. 28 , pp. $235-271$.

[19] Meksyn, D., 1950, “Stability of viscous flow over concave cylindrical surfaces,” Proc.Roy. Soc., Vol. 203, No. 1073, pp. 253265.

[20] Peerhossaini, H. and Bahri, F., 1998, "On the spectral distribution of the modes in non-linear Görtler instability," Experimental Thermal and Fluid Science, Vol. 16, No. 3, pp. 195-208.

[21] Ajakh, A., Kestoras, M.D., Toe, R., and Peerhossaini, H., 1999, "Influence of Forced Perturbation in the Stagnation Region on Görtler Instability,” AIAA Journal, Vol. 37, No. 12, pp. 1572-1577.

[22] Toe, R., Ajakh, A., and Peerhossaini, H., 2002, "Heat transfer enhancement by Görtler instability," Int. J. of Heat and Flow, Vol. 23, No. 2, pp. 194-204.

[23] Mitsudharmadi, H., Winoto, S. H. and Shah, D. A., 2004, "Development of boundary layer flow in the presence of forced wavelength Görtler vortices," Physics of Fluids, Vol. 16, No. 11, pp. 3983-3996.

[24] Lee, K. and Liu, J.T.C., 1992, "On the growth of mushroomlike structures in nonlinear spatially developing Görtler vortex flow," Physics of Fluids A, Vol. 4, No. 1, pp. 95-103.

[25] Bakchinov, A.A., Grek, G.R., Klingmann, B.G.B. and Kozlov, V.V., 1995, “Transition experiments in a boundary-layer with embedded streamwise vortices," Physics of Fluids, Vol. 7, No. 4, pp. 820-832.

[26] Winoto, S.H., Mitsudharmadi, H. and Shah, D.A., 2005, "Visualizing Görtler vortices," J. Visualization, Vol. 8, No. 4, pp. 315-322.

[27] Winoto, S.H. and Crane, R.I., 1980, "Vortex structure in laminar boundary-layers on a concave wall," Int. J. of Heat and Fluid Flow, Vol. 2, No. 4, pp. 221-231.

[28] Finnis, M.V. and Brown, A., 1997, “The linear growth of Görtler vortices,” Int. J. of Heat and Fluid Flow, Vol. 18, No. 4, pp. 389-399.

[29] Schmid, P.J. and Henningson, D.S., 2001, "Stability and transition in shear flows," Applied Mathematical Sciences, Vol. 142, Springer-Verlag, New York .

[30] Wortman, F.X., 1969, "Visualization of transition, J. of Fluid Mechanics," Vol. 38, pp. 473-480.

[31] Aihara, Y. and Koyama, H., 1981, "Secondary instability of Görtler vortices-formation of periodic three-dimensional coherent structure,” Trans.Japan Soc. Aero. Space.Sci., Vol. 24, pp. 78-94.

[32] Swearingen, J.D. and Blackwelder, R.F., 1987, "The growth and the breakdown of streamwise vortices in the presences of a wall," J. of Fluid Mechanics, Vol. 182, pp. 255-290.

[33] Li, F. and Malik, M.R., 1995, "Fundamental and subharmonic secondary instabilities of Görtler vortices," J. of Fluid 
Mechanics, Vol. 297, pp. 77-100.

[34] Sabry, A.S. and Liu, J.T.C., 1991, "Longitudinal vorticity elements in boundary layers: Nonlinear development from initial Görtler vortices as a prototype problem," J. of Fluid Mechanics, Vol. 231, p. 615.

[35] Hall, P. and Horseman, N. J., 1991, "Linear inviscid secondary instability of longitudinal vortex structures in boundary layers," J. of Fluid Mechanics, Vol. 232, p. 357.

[36] Girgis, I. G. and Liu, J.T.C., 2006, "Nonlinear mechanics of wavy instability of steady longitudinal vortices and its effect on skin friction rise in boundary layer flow," Physics of Fluids, Vol. 18 No. 2, 024102.

[37] Tandiono, Winoto, S.H. and Shah, D.A., 2009, "Wall shear stress in Görtler vortex boundary layer flow," Physics of Fluids, Vol. 21, No. 8, 084106.

[38] Bottaro, A., Klingmann, B.G.B. and Zebib, A., 1996, "Goertler vortices with system rotation,” Theoretical and Computational Fluid Dynamics, Vol. 8, No. 5, p. 325.

[39] Guo, Y., and Finlay, W.H., 1994, "Wavenumber selection and irregularity of spatially nonlinear Dean and Görtler vortices, J. of Fluid Mechanics, Vol. 264, pp. 1-40.

[40] Winoto, S.H., Tandiono, Shah, D.A. and Mitsudharmadi, H., 2007, "Flows over concave surfaces: Development of pre-set wavelength Görtler vortices," Proc. $9^{\text {th }}$ Asian International Conference on Fluid Machinery, Jeju, Korea, 16 - 19 October 2007 , Paper No. AICFM9-IL04.
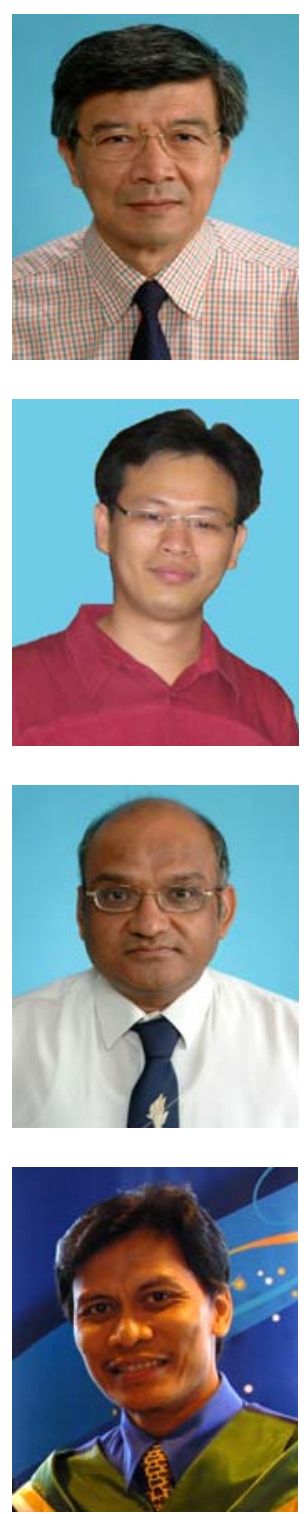

S. H. Winoto He obtained his PhD from Imperial College, London in 1980 and joined the National University of Singapore in the same year. In 1988-89, he was a Visiting Professor at Georgia Institute of Technology and University of Southern California in U.S.A. He chaired some international conferences held in Singapore such as the $9^{\text {th }}$ International Symposium on Transport Phenomena in 1996 and the $7^{\text {th }}$ Asian Symposium on Visualization in 2003. His research interests include concave surface boundary layer flows (for which he has delivered a number of invited lectures at international conferences), jet flows and their application, fluid machinery and recently wind energy. He received the American Society of Mechanical Engineers (ASME) Region XIII in 2001 and the Journal of Visualization Award in 2007.

Tandiono He obtained his PhD from National University of Singapore in 2010, and currently working as a Research Engineer in Institute of High Performance Computing, A*STAR, Singapore. He was awarded the best graduate in the Department of Mechanical Engineering, Institut Teknologi Bandung, Indonesia in 2004, and also a recipient of NUS Research Scholarship (2005-2009). His research interests are boundary layer flows, bubble dynamics, cavitation in microfluidics for biological applications, and sonochemistry.

D. A. Shah He obtained his Master of Engineering from Indian Institute of Science, Bangalore, India in 1980 and $\mathrm{PhD}$ from University of Newcastle, Australia in 1988. He spent about a year as a faculty member at the Indian Institute of Technology, Kunpur, India before joining the National University of Singapore in 1989. His research interests include hot-wire anemometry, structure of turbulent shear flows, bluff bodies, and industrial aerodynamics.

H. Mitsudharmadi He received his Engineering Graduate (Ir.) degree in Mechanical Engineering from University of Indonesia with a major in Energy Conversion in 1993, and his MEng and PhD degrees in Experimental Fluid Mechanics from the Department of Mechanical Engineering, National University of Singapore (NUS) in 2002 and 2007 respectively. Currently he is working as a Research Scientist in the Aeroscience group of Temasek Laboratories at NUS. His research interests are in experimental fluid mechanics such as wake study, boundary layer flows, hot wire anemometry, flow control, particle image velocimeter (PIV) and flow visualization technique. 